\title{
Autoantigen-specific protection of non-obese diabetic mice from cyclophosphamide-accelerated diabetes by vaccination with dendritic cells
}

\author{
T. Krueger ${ }^{1}$, U. Wohlrab ${ }^{1}$, M. Klucken ${ }^{1}$, M. Schott ${ }^{1,2}$, J. Seissler ${ }^{1}$ \\ ${ }^{1}$ German Diabetes Research Institute, University of Düsseldorf, Düsseldorf, Germany \\ 2 Department of Endocrinology, University of Düsseldorf, Germany
}

\section{Abstract}

Aims/hypothesis. Dendritic cells (DCs) are professional antigen presenting cells involved in the initiation of primary immune responses and the preservation of peripheral tolerance. The aim of this study was to develop a DC vaccine for autoantigen-specific prevention of autoimmune diabetes.

Methods. Splenocytes from diabetes-prone NOD mice were cultured in conditioned media to obtain a homogeneous DC sub-population for vaccination experiments. These cells were used to modulate autoimmune responses in NOD mice after synchronization of diabetes with cyclophosphamide. After immunisation with insulin-pulsed DCs the incidence of diabetes, the insulitis grade and the cytokine production was examined. Results. The long-term culture of splenocytes resulted in the generation of a cell line, termed NOD-DC1, which have a phenotype of myeloid DCs (CD11c, CD11b, DEC-205), express MHC class II and co- stimulatory molecules (CD40, CD80, CD86). The NOD-DC1 cells have preserved functional activity shown by the detection of a high antigen uptake capacity, the induction of a mixed lymphocyte reaction and stimuli-dependent IL-6 and TNF- $\alpha$ secretion. Vaccination with insulin-pulsed NOD-DC1 cells results in an antigen-specific prevention of diabetes. This was mediated by a reduction of the severity of insulitis and a decrease of $\mathrm{T}$ helper 1 effector cells.

Conclusion/interpretation. We describe the generation of a DC line which confers protection from diabetes in an antigen-specific way. Our data shows that autoantigen-loaded DCs can induce strong immunoregulatory effects supporting the hypothesis that DCs are promising candidates to develop novel vaccines for the prevention of autoimmune diabetes. [Diabetologia (2003) 46:1357-1365]

Keywords Dendritic cells, vaccination, prevention, Type 1 diabetes, NOD mouse, cyclophosphamide.
Type 1 (insulin-dependent) diabetes is caused by a selective destruction of the insulin-producing beta cells of the pancreas mediated by autoreactive T lympho-

Received: 14 February 2003 / Revised: 30 June 2003

Published online: 20 August 2003

(C) Springer-Verlag 2003

Corresponding author: J. Seissler MD, German Diabetes Research Institute, University of Düsseldorf, Auf'm Hennekamp 65, 40225 Düsseldorf, Germany

E-mail: seissler@ddfi.uni-duesseldorf.de

Abbreviations: APC, antigen-presenting cells; CY, cyclophosphamide; DCs, dendritic cells; LPS, lipopolysaccharide; mAb, monoclonal antibodies; NOD, non-obese diabetic; Th, T-helper cells. cytes. Several lines of evidence suggest that a disturbance of the balance between two T-helper (Th) lymphocyte subsets represent a major pathogenetic element in the development of Type 1 diabetes. Th1 cells, characterised by the secretion of IFN- $\gamma$, activate macrophages and cytotoxic T-cells, and are directly involved in the destruction of beta cells. In contrast, Th2 cells which produce anti-inflammatory cytokines such as IL-4 and IL-10 are associated with protection from Type 1 diabetes $[1,2]$. Although the molecular mechanisms involved in the initiation of beta-cell autoimmunity and the preferential polarisation to Th1 cells are not completely understood, the activation of antigen-presenting cells (APC) could play a role in this process. 
In non-obese diabetic (NOD) mice, a widely used animal model to study the pathogenesis of Type 1 diabetes, it has been shown that macrophages and dendritic cells (DCs) are among the first mononuclear cells that infiltrate the Langerhans' islets in the pre-diabetic period [3, 4]. An increased pro-inflammatory activity of APCs due to hyperactivation of NF-kappaB has been shown in NOD mice that might be involved in the initiation and progression of beta-cell autoimmunity [5]. DCs are the most potent professional APCs with unique abilities to initiate immune responses. Recent studies suggest that DCs are not only involved in the induction of T-cell immunity but also in the regulation and suppression of autoreactive T-cells $[6,7]$. Their capacity to modulate immune responses appears to be dependent on the maturation and activation state. Highly activated mature DCs induce a strong pro-inflammatory Th1-polarised response whereas immature DCs with low expression of costimmulatory molecules and cytokines can induce a state of anergy or tolerance [8,9]. In addition, it has been shown that DCs grown in medium containing IL10 , TGF- $\beta$ or prostaglandin E2 can exert tolerogenic properties by the induction of regulatory T-cells or Th2 cells $[10,11,12,13]$. Thus, the activation state and the micro-environment might play a crucial role in controlling the strength and the balance of autoreactive regulatory or effector cells [9, 14].

Recent studies suggest that in vitro cultured DC can serve as highly potent vaccine for various immunotherapies. Vaccination with activated DC loaded with tumour antigens elicit a strong cytotoxic immunoreactivity which was associated with tumour regression in some cases [15]. With respect to their immunomodulatory properties, it might also be feasible to utilise DC for the development of intervention strategies to treat or prevent autoimmune diseases. In experimental autoimmune encephalomyelitis and collagen-induced arthritis it was reported that vaccination with DCs can downregulate the activity of autoimmune diseases [16]. Protection from diabetes was observed in NOD mice after immunisation with DCs from the local pancreatic lymph nodes [17]. In addition, intraperitoneal injection of DCs isolated from the spleen or bone marrow was found to reduce the incidence of diabetes in NOD mice whether or not the DCs were pulsed with autoantigen $[19,20,21]$. The unspecific immunomodulatory effect has been explained by a general activation of Th2 cells following DC administration. Since the purity of the DC preparation was reported to vary between $87-92 \%$, it can not be excluded that some contaminating monocytes/macrophages or immunosuppressive T-cells have a major influence on the results. In addition, the primary isolation of DCs from bone marrow or the spleen could result in a rather heterogeneous DC population including myeloid- and lymphoid-derived DCs in different activation states conferring immunostimu- latory and/or suppressive abilities. This has made it difficult to distinguish antigen-specific from unspecific vaccination effects.

To overcome these problems, we established a culture system for the long-term expansion of DCs from NOD mouse splenocytes which (i) have characteristic features of myeloid DCs, (ii) possess full functional activity and (iii) can serve as adjuvant for autoantigenspecific immunisation. We show that this DC cell line can be useful to develop a novel vaccine for the antigen-specific prevention of autoimmune diabetes.

\section{Materials and methods}

Animals. NOD mice were obtained from the Diabetes Research Institute breeding colony, where the incidence of diabetes in female mice is $75 \%$ by 40 weeks of age. C57B1/6 mice were obtained from B\&M (Ry, Denmark). Mice were killed under anaesthesia by cervical dislocation. The animal experiments were carried out according to German Law on the Protection of Animals and approved by the Animal Care Committee of North Rhine-Westphalia.

Culture media and antibodies. NIH/3T3 cells were cultured in DMEM with $10 \%$ calf serum, $100 \mathrm{U} / \mathrm{ml}$ penicillin, $100 \mu \mathrm{g} / \mathrm{ml}$ streptomycin (Life Technologies, Karlsruhe, Germany). Supernatants of confluent cells were collected and filtered using a $0.2 \mu \mathrm{m}$ filter (Corning, Wiesbaden, Germany). DCs were cultured in Iscove's modified Dulbecco's medium (IMDM, Sigma, St. Louis, Mo., USA) supplemented with $10 \%$ fetal calf serum (FCS) (Life Technologies), $2 \mathrm{mmol} / \mathrm{l}$ glutamine, 50 $\mu \mathrm{mol} 2 \beta$-mercaptoethanol (ME), $100 \mathrm{U} / \mathrm{ml}$ penicillin and 100 $\mu \mathrm{g} / \mathrm{ml}$ streptomycin, $10 \mathrm{ng} / \mathrm{ml}$ GM-CSF (BD Biosciences, San Diego, Calif., USA) and culture supernatant (30\% v/v) from NIH/3T3 fibroblasts (complete medium, CM).

The following monoclonal antibodies $(\mathrm{mAb})$ were used for the phenotypic analysis of DC: FITC-conjugated anti-CD4 (H129.19), anti-CD80 (16-10-1), anti-CD86 (GL1); PE-conjugated anti-CD8 (53-6-7), anti CD11b (M1/70), anti-CD11c (HL3), anti-CD14 (rmC5-3); unlabelled anti-CD3 (17A2), anti-CD16/32 (2.4G2), anti-CD19 (1D3), anti-CD34 (RAM34), anti-CD40 (3/23), anti-MHC class II I-A ${ }^{\mathrm{K}}$ (10-3.6) (all purchased from BD Biosciences), anti-macrophage F4/80 (CI:A31), and anti-dendritic cell mAb (NLDC-145) (BMA Biochemicals, Augst, Switzerland). PE- and FITC-conjugated rat antimouse IgG and isotype-matched control antibodies were from BD Biosciences.

Generation of the NOD-DC 1 line. To obtain a long-term DCline, spleen cells from an 8-week-old female NOD mouse were isolated by mincing freshly removed spleen through a wire mesh and dispersing tissue clumps by aspiration through a syringe equipped with a $19-\mathrm{G}$ needle. After the lysis of erythrocytes with ammonium chloride ( $3 \mathrm{~min}, \mathrm{RT}$ ), splenocytes were plated into cell culture petri dishes (Corning) at a density of $5 \times 10^{5}$ cells $/ \mathrm{ml}$ in CM. The cells were fed every 3 to 4 days and sub-cultures were made every 2 to 3 weeks. Cells were harvested by extensive pipetting/aspirating to dislodge aggregates of adherent cells and transferred onto new plates. Firmly attached cells were discarded. After 6 months a homogeneous cell line, designated as NOD-DC1 cell line, was obtained. Phenotypic and functional analysis and vaccinations were carried out with NOD-DC1 cells cultured for more than 12 months (passages 30-40). 
Analysis of phenotype by flow cytometry. Suspended and adherent DCs were harvested by incubation in $1 \mathrm{mmol} / \mathrm{l}$ EDTA in PBS for $10 \mathrm{~min}$ at RT. Cells were washed and $0.5-$ $1.0 \times 10^{5}$ cells were suspended in PBS, blocked by pre-incubation with $10 \%$ FCS $\left(20 \mathrm{~min}\right.$ at $\left.4^{\circ} \mathrm{C}\right)$ and incubated for $30 \mathrm{~min}$ at $4^{\circ} \mathrm{C}$ with $\mathrm{mAb}$ against T-cell markers (CD4, CD8), B cells (CD19), haematopoietic stem cells (CD34), costimulatory molecules (CD40, CD80, CD86), MHC class II molecules (I-A ${ }^{\mathrm{K}}$ ), macrophage lineage (F4/80), monocytes/macrophages (CD14), dendritic cell marker DEC 205 (NLDC-145), and receptors/adhesins (CD11b, CD11c). Stained cells were analysed with a FACS Star (Becton Dickinson, Hamburg, Germany).

Measurement of antigen uptake. $1 \times 10^{5}$ DCs were seeded in 24well plates and cultured in CM for 2 days. Phagocytosis and endocytic activity was determined as the cellular uptake of carboxylate modified fluorescent latex beads $\left(1.1 \mu \mathrm{m}, 1 \times 10^{7} \mathrm{mi}-\right.$ crospheres) or $200 \mu \mathrm{g} / \mathrm{ml}$ FITC-labelled albumin (Sigma) at $37^{\circ} \mathrm{C}$ (specific uptake) and $4^{\circ} \mathrm{C}$ (unspecific uptake), respectively. After 5 to $60 \mathrm{~min}$ the uptake was stopped with ice-cold PBS. The cells were washed with PBS and the percentage of positive cells was measured by flow cytometry.

Mixed leukocyte reaction. NOD-DC1 cells were cultured in $\mathrm{CM}$ with or without $10 \mathrm{ng} / \mathrm{ml}$ lipopolysaccharide (LPS) for $24 \mathrm{~h}$. Then cells were harvested, irradiated (3000 rad) and added in graded doses $\left(2 \times 10^{3}-4 \times 10^{4}\right.$ cells per well $)$ to $2 \times 10^{5}$ purified allogeneic T-cells/well in 96-well plates. T-cells were prepared by negative selection from C57BL/6 mice using CD3+ T-cell purification columns (R\&D Systems, Wiesbaden, Germany) according to the manufacturer's instructions. Proliferation was measured in triplicates by addition of $37 \mathrm{kBq} /$ well $\left[{ }^{3} \mathrm{H}\right]$-thymidine for the last $18 \mathrm{~h}$ of a 3 -day incubation period. The incorporation of $\left[{ }^{3} \mathrm{H}\right]$-thymidine was measured in a liquid scintillation counter.

Immunization with dendritic cells. To accelerate and synchronize diabetes, female 8-week-old NOD mice were treated with a single i.p. injection of cyclophosphamide (CY) $(200 \mathrm{mg} / \mathrm{kg}$ body weight). Mice were then randomly divided into treatment and control groups. To assess the tolerizing effect of IL-10 one experiment was done where NOD-DC1 cells were pulsed with insulin $(400 \mu \mathrm{g} / \mathrm{ml}$ for $6 \mathrm{~h})$ without IL-10 pretreatment. In all other experiments NOD-DC1 cells were pre-treated for 3 days with IL-10 (20 ng/ml) (BD Biosciences). Cells were then pulsed with insulin $(400 \mu \mathrm{g} / \mathrm{ml})$ or ovalbumin $(400 \mu \mathrm{g} / \mathrm{ml}) 6 \mathrm{~h}$ before harvesting.

Cells were collected by treatment with $1 \mathrm{mmol} / \mathrm{l}$ EDTA in PBS (10 min, RT), washed three times and $4 \times 10^{5}$ NOD-DC1 cells were injected i.p. at day 2 after CY treatment. Mice were monitored by daily glucosuria analysis which was confirmed by blood glucose measurement (hexokinase method). Diabetes was diagnosed when the blood glucose concentration were above $300 \mathrm{mg} / \mathrm{ml}(16.7 \mathrm{mmol} / \mathrm{l})$.

Measurement of cytokine mRNA expression. In each vaccination group three mice were used at day 10 after CY treatment for the analysis of pancreatic IL-10 and IFN- $\gamma$ mRNA expression by quantitative real-time RT-PCR using the LightCycler system (Roche Diagnostics, Mannheim, Germany). Total RNA was isolated from the pancreas by guanidinium thiocyanatephenol-chloroform extraction and $1 \mu \mathrm{g}$ was reverse transcribed into cDNA using the first strand cDNA synthesis kit (Roche Diagnostics) [22].

To generate control templates for the quantification we cloned a $\beta$-actin fragment (bp 79-1232; GenBank accession number NM 007393), and full length $I L-10$ (NM 010548) and
$I F N-\gamma$ (XM 125899) from mouse spleen by RT-PCR into the pGEM 4Z vector (Promega). Plasmids were linearised by restriction enzyme digestion and diluted to a set of four concentrations ranging from $10^{7}$ to $10^{4}$ copies ( $\beta$-actin), and $10^{4}$ to $10^{1}$ copies $(I L-10, I F N-\gamma)$, respectively. To generate standard curves, the crossing cycle numbers of the logarithmic-linear PCR phase (crossing points) of the standards were plotted versus the logarithm of their concentrations [23]. Each real-time PCR was carried out with an initial denaturation step of $10 \mathrm{~min}$ at $95^{\circ} \mathrm{C}$ and an amplification for 40 cycles using the following conditions:

$\beta$-actin forward $5^{\prime}$-ACCCACACTGTGCCCATCTA-3', reverse $5^{\prime}$-GCCACAGGA-TTCCATACCCA-3', $15 \mathrm{~s}$ at $95^{\circ} \mathrm{C}, 5 \mathrm{~s}$ at $58^{\circ} \mathrm{C}$ and $15 \mathrm{~s}$ at $72^{\circ} \mathrm{C}\left(3 \mathrm{mmol} / 1 \mathrm{MgCl}_{2}\right)$;

IL-10 forward 5'-AGCTGGACAACATACTGCTAAC-3', reverse 5'-CTCTTATTTTC-ACAGGGGAGAA-3', $15 \mathrm{~s}$ at $95^{\circ} \mathrm{C}, 5 \mathrm{~s}$ at $58^{\circ} \mathrm{C}$ and $12 \mathrm{~s}$ at $72^{\circ} \mathrm{C}(4 \mathrm{mmol} / 1$ $\mathrm{MgCl}_{2}$ );

IFN- $\gamma$ forward 5'-CAGCAACAACATAAGCGTCAT-3', reverse 5'-GCAGCGACTCC-TTTTCCGCTT-3', $15 \mathrm{~s}$ at $95^{\circ} \mathrm{C}, 5 \mathrm{~s}$ at $59^{\circ} \mathrm{C}$ and $10 \mathrm{~s}$ at $72^{\circ} \mathrm{C}(3 \mathrm{mmol} / 1$ $\mathrm{MgCl}_{2}$ ).

To exclude inter-assay variations all cDNAs and standards were run in parallel in one PCR reaction. The constitutively expressed housekeeping gene $\beta$-actin was used to normalise the probes to equal cDNA contents.

Cytokine assays. The capacity of the NOD-DC1 cells to produce cytokines was assessed by the measurement of IL-6, IL12 and TNF- $\alpha$ in culture supernatant fluids after stimulation with LPS (1-1000 $\mathrm{ng} / \mathrm{ml})$ for $24 \mathrm{~h}$. In some experiments cells were pre-cultured for 3 days in CM supplemented with IL-10 (20 ng/ml) before LPS stimulation.

To determine T-cell cytokine secretion patterns splenocytes from NOD mice treated with either insulin- or ovalbuminloaded NOD-DC1 cells were isolated at day 10 after CY treatment. Cells $\left(3 \times 10^{6}\right)$ were cultured in 24 -well plates in RPMI supplemented with $10 \%$ FCS, $50 \mu \mathrm{mol} \mathrm{ME}, 1 \mathrm{mmol} / \mathrm{l}$ sodium pyruvate, $100 \mathrm{U} / \mathrm{ml}$ penicillin, $100 \mu \mathrm{g} / \mathrm{ml}$ streptomycin (Life Technologies) and $50 \mu \mathrm{g} / \mathrm{ml}$ insulin. After 3 days culture supernatants were harvested. Measurements of mouse IL-6, IL-10, IL-12p70, TNF- $\alpha$ and IFN- $\gamma$ concentrations were carried out in duplicate by sandwich ELISA Sets according to the manufacturer's instructions (BD Biosciences; R\&D Systems, Minneapolis, Minn., USA).

T-cell response to insulin was also analysed by ELISPOT using IFN- $\gamma$ ELISPOT development modules (R\&D Systems). Splenocytes $\left(1 \times 10^{5} /\right.$ well $)$ were incubated in triplicate wells in IMDM medium supplemented with $1 \%$ normal mouse serum, $100 \mathrm{U} / \mathrm{ml}$ penicillin, $100 \mu \mathrm{g} / \mathrm{ml}$ streptomycin and $50 \mu \mathrm{g} / \mathrm{ml}$ insulin. After $24 \mathrm{~h}$ the plates were developed according to the manufacturer's instructions. Data were expressed as spot-forming colonies (SFC) per well.

Immunohistochemical analysis. Cryostat sections $(4 \mu \mathrm{m})$ of pancreata from immunised or control mice at day 10 after CY treatment were cut at $100 \mu \mathrm{m}$ intervals and stained with haematoxylin/eosin. The degree of beta-cell damage and the infiltration with mononuclear cells (insulitis) was scored under a Zeiss photomicroscope (Zeiss, Jena, Germany) [24]. All islets in 10 sections were evaluated (more than 80 islets per animal) and insulitis was graded into four grades: grade 0: normal islets without any infiltration, grade 1: mild insulitis (perinsulitis), grade 3: severe insulitis with infiltration and beta-cell destruction, grade 4: completely destroyed islets. 


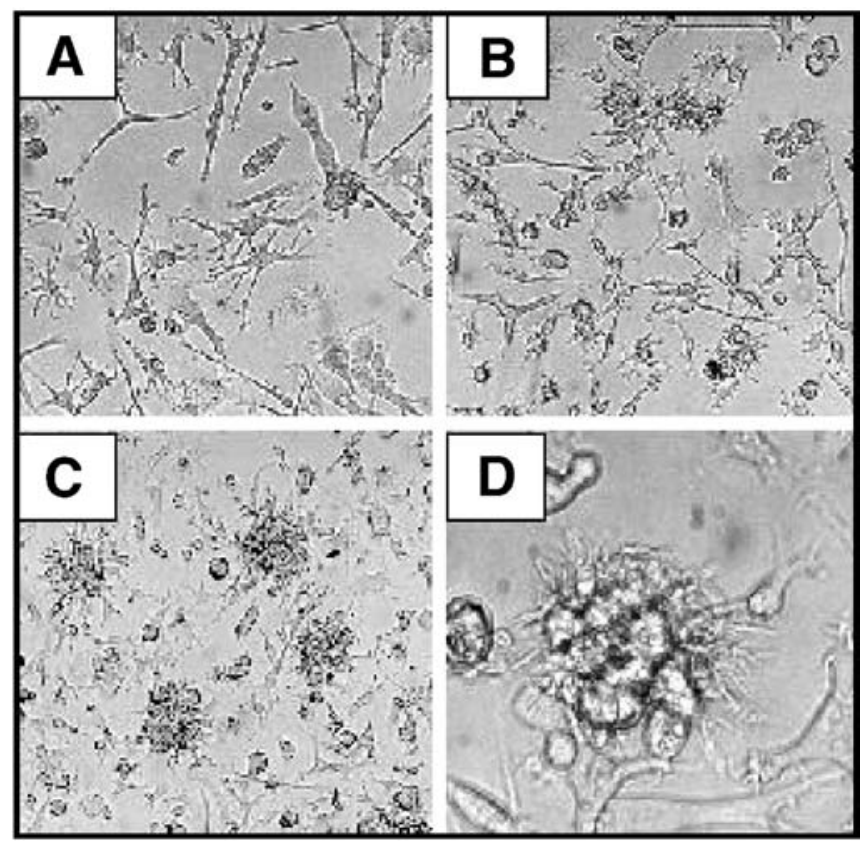

Fig. 1A-D. Phase contrast microscopy of NOD-DC1 cells at different times after transfer into a new plate. (A) Adherent cells with few long dendrites at day 2. (B) Development of focal confluent with central loosely adherent round cells (day 6). (C) Appearance of cells clusters with DC-like shape (day 10). (D) Single cell cluster from $C$ examined at higher magnification shows the presence of numerous veils-like cytoplasmic cell processes

Statistical analysis. Data are presented as mean values and SD of at least three independent experiments. Differences between groups were determined by either Student's $t$ test or ANOVA testing. The incidence of diabetes was analysed using the Kaplan Meier method. A $p$ value of less than 0.05 was considered statistically significant.

\section{Results}

The NOD-DC 1 cell line share features of dendritic cells. The culture of spleen cells in GM-CSF conditioned medium results in the generation of a long-term cell line. These cells now grow over more than 24 months and are strictly dependent on the presence of the growth factor GM-CSF. Removal of GM-CSF results in a decrease of proliferation and subsequent cell death. Analysis at the microscopic level revealed that these cells undergo a co-ordinate change in their morphology depending on the cell density (Fig. 1). After seeding the cells grew as single, loosely adherent cells with few long dendrites. In the second state the cells form focal confluent aggregates that harbour several round cells in their centre. Then an increasing number of cell clusters appeared which are formed by round or oval cells with typical dendritic shape (numerous veilor sheet-like cytoplasmic processes). Those DC-like cells were used for analysis of phenotype, measurement of functional activity and vaccination experiments.
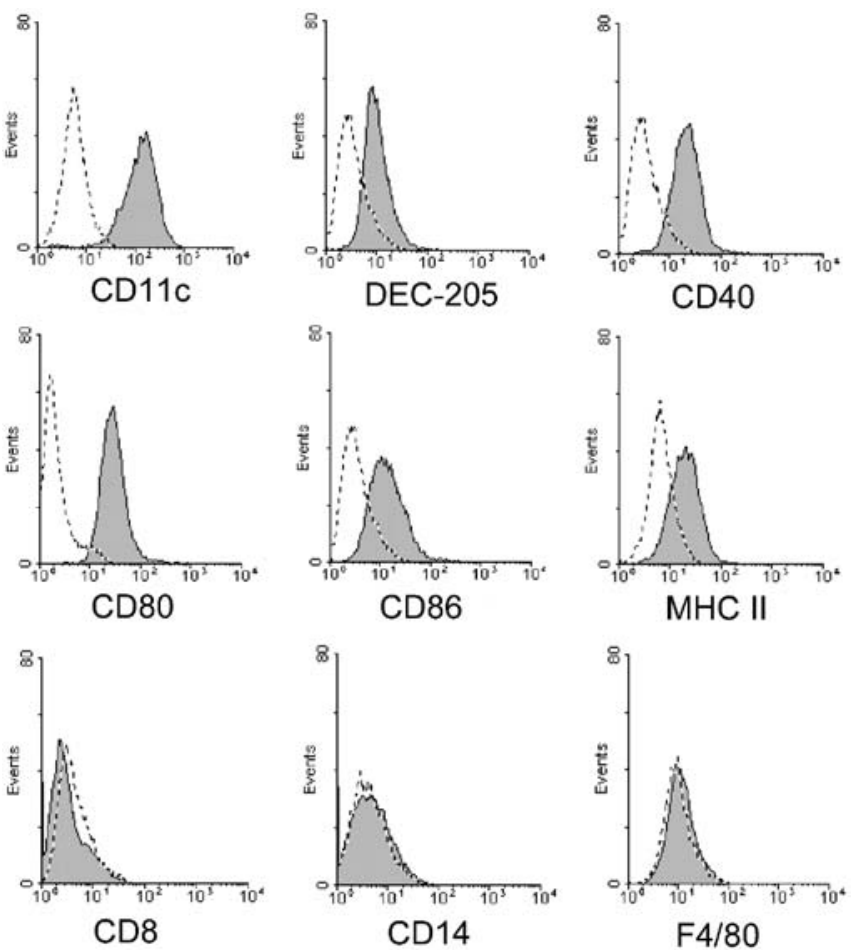

Fig. 2. NOD-DC1 cells express characteristic markers of myeloid DCs. Cells were stained with anti-CD8, -CD11c, -CD14, -CD40, -CD80, -CD86, -DEC-205, -MHC class II, -F4/80 (heavy lines), and isotype-matched control antibodies (dotted lines) followed by FACS analysis

To ascertain the identity of the cell line, we examined the expression of surface markers by FACS analysis. After passaging for 10 days, the cells expressed markers known to be associated with mouse DCs, for example, CD11c, CD40, CD86 and MHC class II. In addition, 50 to $60 \%$ had positive staining for the DCrestricted marker DEC-205. Staining for T-cell markers (CD4 and CD8), macrophages/monocytes (CD14, F4/80), B cells (CD19) and CD34+ stem cells was negative. These data show that the cultured cell line shares characteristic features of DCs (Fig. 2). Therefore, this cell line was designated NOD-DC1.

Functional capacity of NOD-DCl cells. A characteristic of DCs is a high antigen uptake by phagocytosis and macropinocytosis. To examine the capacity of the NOD-DC1 cells, we measured the uptake of FITC-labelled latex beads and FITC-labelled albumin. There was a time-dependent antigen loading of NOD-DC1 cells at $37^{\circ} \mathrm{C}$ whereas at $4^{\circ} \mathrm{C}$ no relevant uptake was observed (Fig. 3). The ability of NOD-DC1 to stimulate T-cells was tested in MLR. Dependent on the ratio DCs: responder cells, NOD-DC1 cells were potent inducers of allogeneic T-cell proliferation. Allostimulatory activity was further increased after cell pre-activation with $10 \mathrm{ng} / \mathrm{ml}$ LPS for $24 \mathrm{~h}$ suggesting that pro-inflammatory agents promote the cell differentiation in a highly activated state (Fig. 4). The functional 

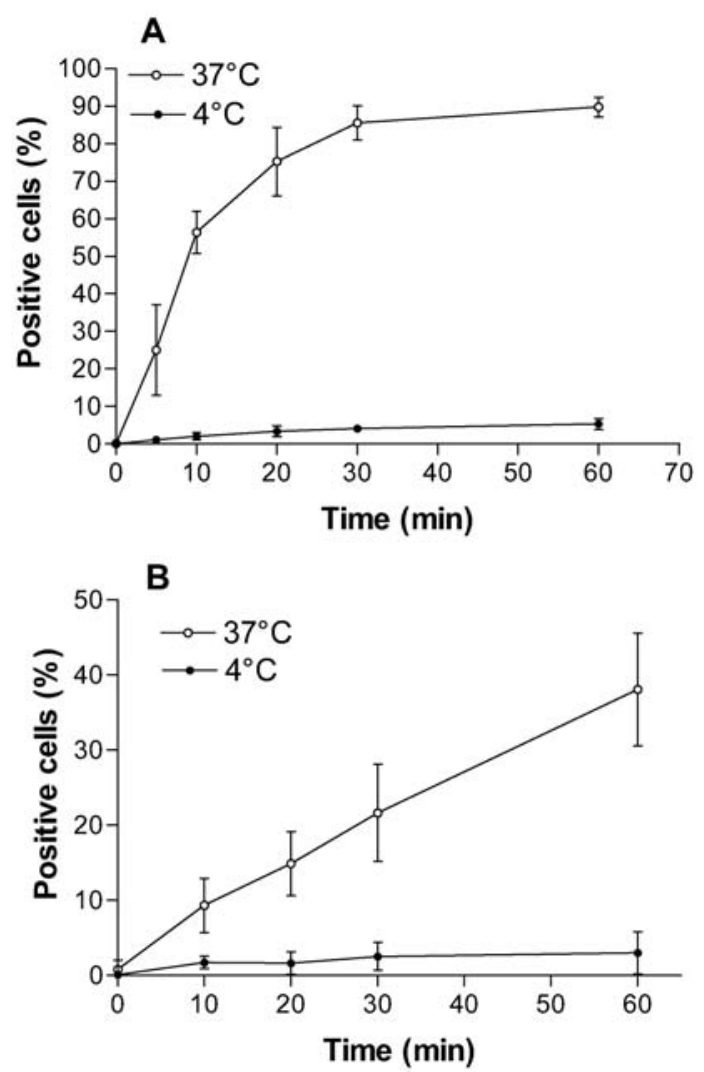

Fig. 3A, B. Flow cytometric analysis of endocytic activity. (A) NOD-DC1 cells $\left(1 \times 10^{5}\right)$ were incubated with $200 \mu \mathrm{g} / \mathrm{ml}$ FITClabelled albumin at $37^{\circ} \mathrm{C}$ or $4^{\circ} \mathrm{C}$ for $5-60 \mathrm{~min}$. (B) NOD-DC1 cells $\left(1 \times 10^{5}\right)$ were incubated with $1 \times 10^{7}$ fluorescent-labelled latex beads $(B)$ at $37^{\circ} \mathrm{C}$ or $4^{\circ} \mathrm{C}$ for $10-60 \mathrm{~min}$. After washing, the cells were analysed by FACS

activity of DCs is dependent on the expression of costimulatory molecules and cytokine secretion. Therefore, we measured IL- 6 , IL-12p70 and TNF- $\alpha$ in cell culture supernatants after treatment of DCs with LPS. LPS induced a strong dose-dependent increase of cytokine production reaching a maximum at $1000 \mathrm{ng} / \mathrm{ml}$ for IL-6 $(17.1 \pm 5.1 \mathrm{ng} / \mathrm{ml})$ and TNF- $\alpha$ (12.3 \pm 0.9 $\mathrm{ng} / \mathrm{ml}$ ) (Fig. 5). In contrast, secretion of bioactive IL12 p70 was only slightly increased $(0.021 \pm 0.008$ $\mathrm{ng} / \mathrm{ml})$.

The activity of NOD-DCl cells can be modulated by $I L-10$. Since it is known that IL-10 can convert DCs into tolerizing APCs, we measured stimuli-dependent cytokine secretion after pre-treatment of NOD-DC1 cells with IL-10 for 3 days. Under basal conditions there was no measurable effect on cytokine secretion. However, IL-10 mediates a partial resistance to the LPS-induced secretion of proinflammatory cytokines (Fig. 5).

Immunisation with insulin-pulsed DCs prevents development of diabetes. To address the question as to whether immunisation with NOD-DC1 cells can in-

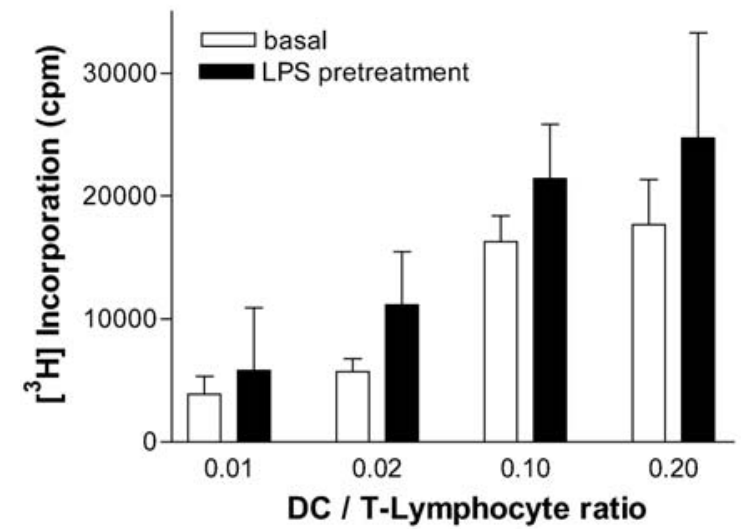

Fig. 4. NOD-DC1 cells induce a strong mixed leukocyte reaction. DCs were cultured with or without $10 \mathrm{ng} / \mathrm{ml}$ LPS for $24 \mathrm{~h}$, washed and cultured at graded doses with $2 \times 10^{5}$ purified CD3+ allogeneic T-cells. Proliferation was measured by $\left[{ }^{3} \mathrm{H}\right]$ thymidine incorporation after 3 days
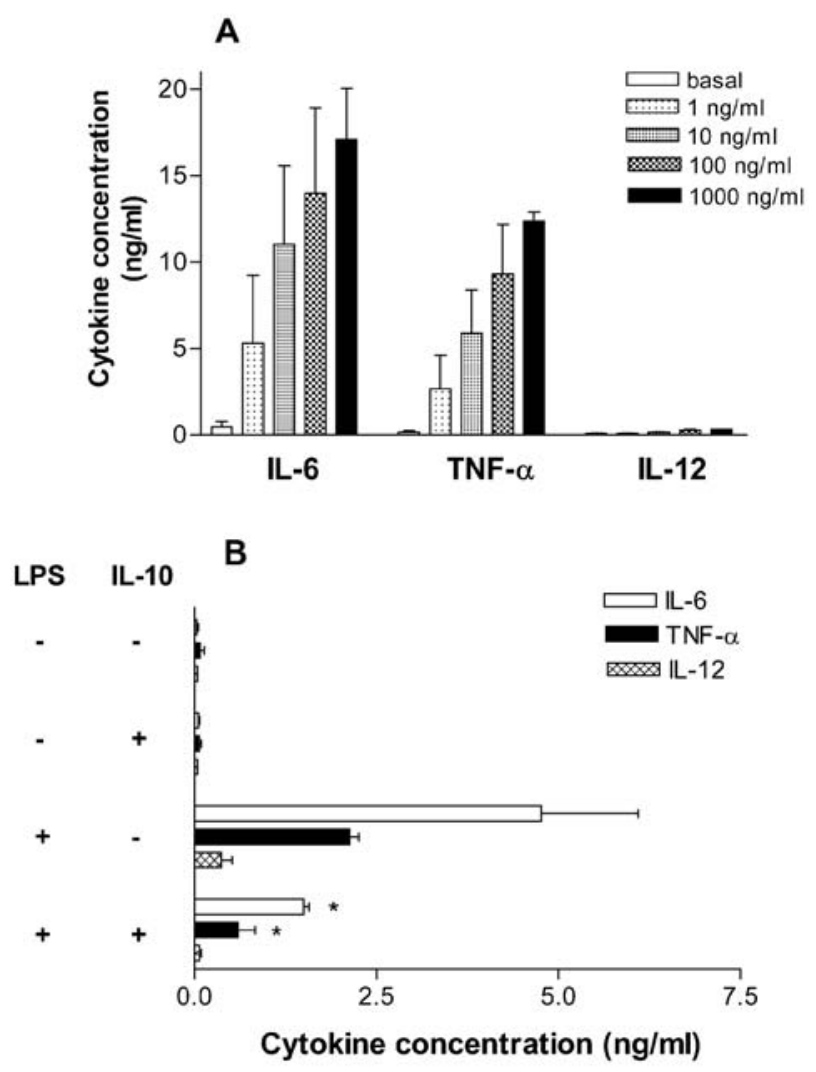

Fig. 5A, B. Effect of stimulatory agents on cytokine secretion. (A) NOD-DC1 cells $\left(3 \times 10^{5} / \mathrm{ml}\right)$ were stimulated with LPS $(1-1000 \mathrm{ng} / \mathrm{ml})$ for $24 \mathrm{~h}$. (B) When the cells were pre-exposed to IL-10 (20 ng/ml) for 3 days and then stimulated with LPS ( $1 \mathrm{ng} / \mathrm{ml}$ ), a lower secretion of IL- 6 and TNF- $\alpha$ was observed. $24 \mathrm{~h}$ accumulation of cytokines were measured in the cell culture supernatant by ELISA. ${ }^{*} p<0.02$ vs treatment without IL-10

duce protection from diabetes, diabetes was synchronized with CY followed by administration of either insulin or ovalbumin loaded NOD-DC1 cells. As IL-10 exerts immunomodulating effects on NOD-DC1 cells 


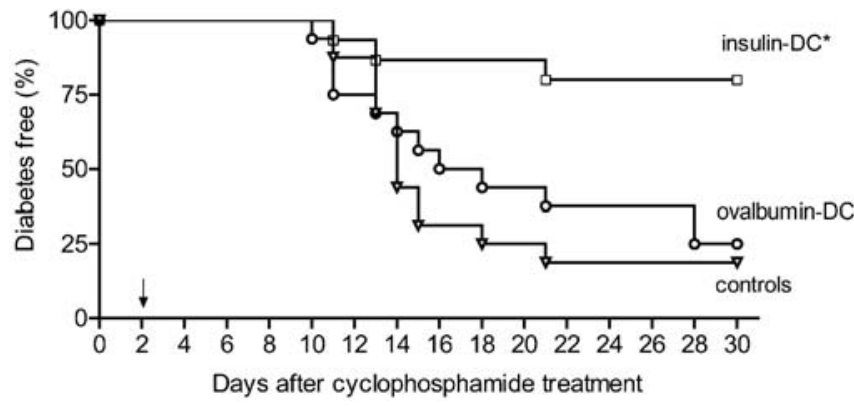

Fig. 6. Prevention of diabetes by vaccination with insulinpulsed NOD-DC1 cells. NOD mice were immunised at day 2 after CY-treatment by i.p. injection of $4 \times 10^{5}$ NOD-DC1 cells which were treated with IL-10 for 3 days and either pulsed with insulin $(n=15)$ or ovalbumin $(n=16)$. An additional control group of mice received only CY $(n=16)$. ${ }^{*} p<0.001$ vs controls and $p<0.003$ vs ovalbumin-pulsed DC

in vitro, we first studied the influence of IL-10 pretreatment on diabetes development after vaccination with insulin loaded DCs in a small group of animals $(n=5-6)$. The use of IL-10 pre-treated, insulin pulsed NOD-DC1 cells prevents diabetes development (diabetes in one of five animals) whereas cells loaded with insulin in the absence of IL-10 had a lower effect (diabetes in three of six animals).

Since these data suggest that IL-10 increases the tolerogenic capacity of NOD-DC1 cells, IL-10 pretreated DCs were chosen for further vaccination experiments. By the follow-up of 30 days after $\mathrm{CY}$ administration, diabetes occurred in 3 of 15 (20\%) mice immunised with insulin-pulsed DCs, while 13 of 16 $(81 \%)$ untreated mice and 12 of $16(75 \%)$ ovalbuminDC treated mice became diabetic, respectively. Life table analysis showed a highly significant reduction of diabetes development in the insulin-DC group as compared to ovalbumin-DC treatment $(p<0.003)$ and control mice $(p<0.001)$ (Fig. 6).

In line with these results, the majority $(68 \%)$ of islets from control mice showed massive infiltration and destruction of pancreatic beta cells (grade 3-4 insulitis) at day 10 after CY administration. Lower insulitis grades were observed in mice immunised with insulin-pulsed DCs (Fig. 7) $(p<0.01)$. In addition, the percentage of non-infiltrated islets was higher in the insulin-DC group (44\%) as compared to the control group (2\%).

To identify mechanisms accounting for the reduced diabetes incidence in insulin-DC treated NOD mice, expression of cytokines associated with Th1 and Th2 cells, namely IFN- $\gamma$ and IL-10, were measured in splenocytes after insulin stimulation and in pancreas tissues. At day 10 after CY treatment splenocytes stimulated with insulin produced lower amounts of IFN- $\gamma$ but higher concentrations of IL-10 as compared mice treated with ovalbumin-pulsed DCs (Fig. 8B). In addition, the frequency of IFN- $\gamma$-producing SFC was lower in mice vaccinated with insulin-pulsed DCs as compared to the ovalbumin-DC group (Fig. 8C).

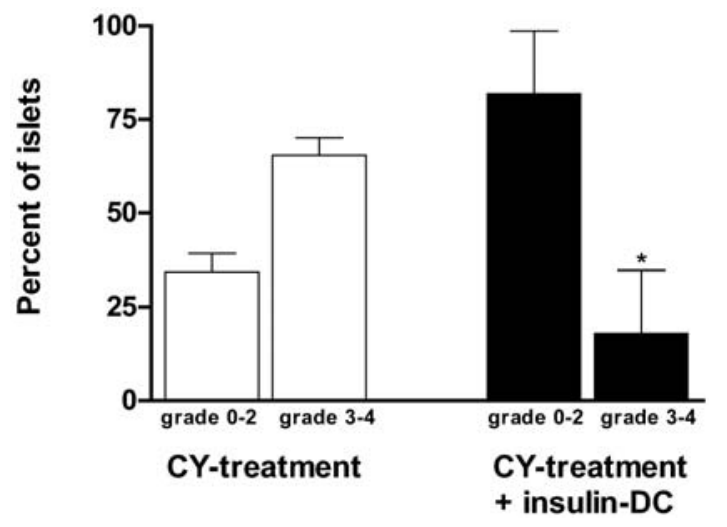

Fig. 7. Histological analysis of pancreatic islets. At day 10 after CY-treatment infiltration of pancreatic islets were graded. Vaccination with IL-10 pre-treated, insulin-pulsed NOD-DC1 results in lower intra-islet insulitis and islet cell destruction as compared to mice treated with CY only. ${ }^{*} p<0.01$ vs insulin-DC
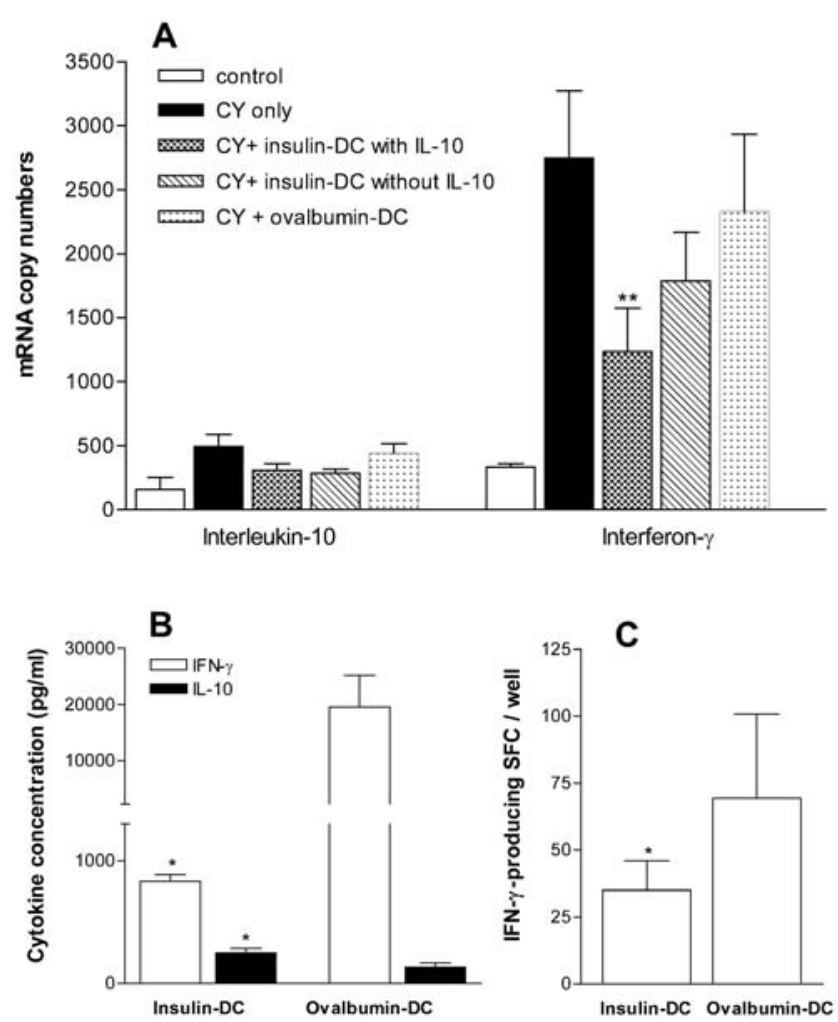

Fig. 8A-C. Vaccination with insulin-pulsed NOD-DC1 cells induced a change in Th1/Th2 balance. At day 10 after CYtreatment $I L-10$ and $I F N-\gamma$ expression was measured. (A) Cytokine expression in the pancreas detected by Light Cycler RTPCR. The number of mRNA copies are expressed per $1 \times 10^{6} \beta$ actin molecules. (B) Cytokine secretion in culture supernatants after stimulation of $3 \times 10^{6}$ splenocytes with $50 \mu \mathrm{g} / \mathrm{ml}$ insulin for 3 days. (C) ELISPOT analysis of insulin-specific T-cell reactivity in NOD mice following vaccination with NOD-DC-1 cells. The frequency of IFN- $\gamma$ spot-forming colonies (SFC) per well in response to $50 \mu \mathrm{g} / \mathrm{ml}$ insulin were calculated from triplicates of individual mice. $* p<0.05$ vs ovalbumin-DC treatment; $* * p<0.05$ vs CY-treatment only 
Real-time RT-PCR measurements of pancreatic cytokine expression showed that both mice that received CY treatment only and mice immunised with ovalbumin-pulsed DCs had a huge increase in IFN- $\gamma$ gene expression. In contrast, immunisation with insulin-pulsed DC resulted in a reduction of pancreatic $I F N-\gamma$ mRNA concentrations, while IL-10 gene expression was similar in all groups of animals (Fig. 8A). Interestingly, in mice that received insulin pulsed NOD-DC1 cells without IL-10 pre-treatment the pancreatic $I F N-\gamma$ expression was lower as compared to the control groups, but less pronounced than in mice that received IL-10 insulin-NOD-DC1 cells supporting the hypothesis of a critical role for IL-10 in the modulation of the DC function. These data indicate that vaccination with IL-10-treated, insulin loaded NOD-DC1 cells induced a clear autoantigendependent switch from a predominant Th1 immune response towards a Th2-type response.

\section{Discussion}

DCs are thought to be involved in the maintenance of peripheral tolerance and the induction of immunoregulatory T-cells. In this study, we have shown that by in vitro culturing of spleen cells a homogeneous population of DCs can be isolated that possess the capacity to modulate beta-cell autoimmunity. The main finding of our study is that this DC sub-population can be pulsed with insulin and used as autoantigen-specific vaccine to prevent the development of autoimmune diabetes in NOD mice.

In NOD mice several immunosuppressive regimens have been shown to provide some protection from diabetes [25, 26]. However, it is clear that an islet cell- or autoantigen-specific immunomodulation is the approach of choice with regard to human Type 1 diabetes. Due to the major role of DCs in the direction of immune responses, we aimed to develop a novel DC vaccination protocol. We considered two points to be of note for the use of DCs as adjuvant to block diabetes development on NOD mice. Firstly, DCs should be available in large quantities in a similar activation and maturation state. Secondly, as several subsets of DCs have different immunostimulatory capacities, stringent conditions are needed to isolate a given DC sub-population in high purity. To achieve these requirements, we decided to generate a long-term DC line from NOD mice which resembles the functional capacity of primary DCs and can serve as a homogeneous source for cell vaccination. Using a modified protocol previously described for the isolation of dendritic cells from the spleen and Langerhans dermal DCs [27, 28], we were able to isolate a novel cell line, termed NODDC1. The NOD-DC1 cells expressed the surface markers CD11c, CD11b, DEC-205, and intermediate values of co-stimulatory molecules (CD40, CD80,
CD86) and MHC class II which have been described as characteristic features of immature myeloid DCs in various studies $[14,29,30]$. It is important to note that the NOD-DC1 cells maintained a stable phenotype throughout the study and grew strictly dependent on the presence of GM-CSF and unknown factors in the 3T3 supernatant. The lack of CD14+ monocytes and CD34+ haematopoeitic stem cells suggest that we have isolated a thus far undefined progenitor/stem cell population from which mature DCs continuously develop.

By analysing the antigen uptake, the allostimulatory activity and the stimulus-mediated cytokine secretion, we have shown that the NOD-DC1 cells have fundamental functional capacities previously described in primary DCs isolated from the spleen, bone-marrow or peripheral blood [9, 14, 29, 30, 31]. LPS induced a strong concentration- and time-dependent rise in the secretion of TNF- $\alpha$ and IL-6 up to 93fold and 36-fold of the basal conditions, respectively. IL-12p70 was undetectable at baseline conditions and was found only slightly increased around the detection limit of the ELISA even at high LPS concentrations. These findings suggest that we might have isolated a DC subtype which is either intrinsically pre-programmed to produce low IL-12 concentrations [32] or our culture conditions favour the generation of not fully activated DCs $[33,34]$. In addition, we showed that the NOD-DC1 activation state and the in vivo immunization effect can be modulated by pre-treatment with IL-10 which is known to suppress DC maturation, decrease antigen-specific stimulation of Th1 cells and, in some cases, increase induction of Th2 cells or regulatory T-cells $[10,12,35,36]$. The tolerogenic phenotype of IL-10 pre-treated NOD-DC1 cells prompted us to investigate whether these cells can be used to prevent diabetes in NOD mice.

To determine the effects of DC-vaccination on the development of autoimmune diabetes, we synchronized diabetes development in NOD mice by the treatment with cyclophosphamide. This is a well established model to study the effects of immunomodulatory agents that has the advantage that immunisation is carried out in animals suffering from a similar strength of autoimmunity with a rapid progressive disease which normally leads to overt diabetes within a period of only 30 days $[37,38]$.

In this study we show that immunization with in vitro insulin-loaded DCs results in protection from diabetes in NOD mice. We chose insulin as an autoantigen because it is the only thus far known beta-cell specific autoantigen and insulin-specific T-cells have been shown in high frequencies in islet infiltrates [39]. Our data on a specific protection from diabetes by DC vaccination are in agreement with a previous study which described prevention from diabetes after injection of DCs isolated from local pancreatic lymph nodes of NOD mice which might have sampled auto- 
antigens from destructed islets [18]. Studies in other autoimmune diseases such as experimental autoimmune encephalomyelitis and collagen-induced arthritis also reported on a specific prevention of disease development after DC vaccination [17, 40, 41]. However, in contrast to our observation, previous studies have shown an autoantigen-unspecific protection from diabetes after transfer of DCs in NOD mice [19, 20, 21]. These inconsistent results could be due to differences in the origin of the DCs, the culture condition chosen and the pre-treatment with IL-10. It can be speculated that freshly isolated DCs could contain various DC sub-populations that direct T-cell differentiation in different ways or contain some contaminating immunoregulatory cells leading to an unspecific stimulation of the Th2 immune system. We show that vaccination with insulin-pulsed DCs was associated with a reduction of insulitis and beta-cell destruction, a decreased pancreatic IFN- $\gamma$ expression and a decreased IFN- $\gamma$ release from T-cells in response to insulin, while in recipients of ovalbumin-DCs no effect was observed. As these effects were dependent on the pre-treatment with IL-10, our data confirm previous reports on a critical role for IL-10 in the induction of tolerogenic DCs. Our findings are consistent with data generated with other immunomodulatory protocols that a reduction of Th1-like effector T-cells and/or a shift into the direction of a regulatory $\mathrm{Th} 2$ response is associated with protection from diabetes in NOD mice [42]. Several studies reported on different mechanisms by which immune deviation is achieved after DC vaccination including promotion of Th2 differentiation from naive T-cells [12], induction of regulatory T-cells [43] or anergy of pathogenic Th1 cells [10]. Although our data indicate that treatment with insulin-loaded DCs results in suppression of IFN- $\gamma$ producing effector T-cells, the complexity of the regulation of the autoimmune response in NOD mice suggests that different components of regulatory pathways could be operational after administration of DCs. Further studies are required to characterise the mechanisms whereby NOD-DC1 cells induce antigen-specific tolerance and diabetes protection.

In summary, our method for the isolation of a longterm DC line allows the generation of a homogeneous source of tolerizing DCs. Vaccination with insulinloaded NOD-DC1 cells results in prevention of CYaccelerated diabetes by the suppression of pathogenic effector T-cells. These data could have important implications for the development of DC-based vaccination protocols for specific prevention of spontaneous autoimmune diabetes.

Acknowledgements. The study was supported by a grant from the the Lilly Foundation International (J.S.) and the Deutsche Diabetes-Gesellschaft (J.S.).

\section{References}

1. Nicholson LB, Kuchroo VK (1996) Manipulation of the Th1/Th2 balance in autoimmune disease. Curr Opin Immunol 8:837-842

2. Kolb H (1997) Benign versus destructive insulitis. Diabetes Metab Rev 13:139-146

3. Jansen A, Homo-Delarche F, Hooijkaas H, Leenen PJ, Dardenne M, Drexhage HA (1994) Immunohistochemical characterization of monocytes-macrophages and dendritic cells involved in the initiation of the insulitis and beta-cell destruction in NOD mice. Diabetes 43:667-675

4. Dahlen E, Dawe K, Ohlsson L, Hedlund G (1998) Dendritic cells and macrophages are the first and major producers of TNF-alpha in pancreatic islets in the nonobese diabetic mouse. J Immunol 160:3585-3593

5. Sen P, Bhattacharyya S, Wallet M et al. (2003) NF-kappa B hyperactivation has differential effects on the APC function of nonobese diabetic mouse macrophages. J Immunol 170:1770-1780

6. Hawiger D, Inaba K, Dorsett Y et al. (2001) Dendritic cells induce peripheral $\mathrm{T}$ cell unresponsiveness under steady state conditions in vivo. J Exp Med 194:769-779

7. Jonuleit H, Schmitt E, Steinbrink K, Enk AH (2001) Dendritic cells as a tool to induce anergic and regulatory $\mathrm{T}$ cells. Trends Immunol 22:394-400

8. Cella M, Sallusto F, Lanzavecchia A (1997) Origin, maturation and antigen presenting function of dendritic cells. Curr Opin Immunol 9:10-16

9. Liu YJ (2001) Dendritic cell subsets and lineages, and their functions in innate and adaptive immunity. Cell 106:259-262

10. Steinbrink K, Wolfl M, Jonuleit H, Knop J, Enk AH (1997) Induction of tolerance by IL-10-treated dendritic cells. J Immunol 159:4772-4780

11. Kalinski P, Hilkens CM, Snijders A, Snijdewint FG, Kapsenberg ML (1997) Dendritic cells, obtained from peripheral blood precursors in the presence of PGE2, promote Th2 responses. Adv Exp Med Biol 417:363-367

12. Liu L, Rich BE, Inobe J, Chen W, Weiner HL (1998) Induction of Th2 cell differentiation in the primary immune response: dendritic cells isolated from adherent cell culture treated with IL-10 prime naive CD4+ T cells to secrete IL4. Int Immunol 10:1017-1026

13. King C, Davies J, Mueller R et al. (1998) TGF-beta1 alters APC preference, polarizing islet antigen responses toward a Th2 phenotype. Immunity 8:601-613

14. Banchereau J, Steinman RM (1998) Dendritic cells and the control of immunity. Nature 392:245-252

15. Steinman RM, Dhodapkar M (2001) Active immunization against cancer with dendritic cells: the near future. Int J Cancer 94:459-473

16. Huang YM, Yang JS, Xu LY, Link H, Xiao BG (2000) Autoantigen-pulsed dendritic cells induce tolerance to experimental allergic encephalomyelitis (EAE) in Lewis rats. Clin Exp Immunol 122:437-444

17. Morita Y, Yang J, Gupta R et al. (2001) Dendritic cells genetically engineered to express IL-4 inhibit murine collagen-induced arthritis. J Clin Invest 107:1275-1284

18. Clare-Salzler MJ, Brooks J, Chai A, Van Herle K, Anderson C (1992) Prevention of diabetes in nonobese diabetic mice by dendritic cell transfer. J Clin Invest 90:741-748

19. Feili-Hariri M, Dong X, Alber SM, Watkins SC, Salter RD, Morel PA (1999) Immunotherapy of NOD mice with bone marrow-derived dendritic cells. Diabetes 48:2300-2308

20. Papaccio G, Nicoletti F, Pisanti FA, Bendtzen K, Galdieri M (2000) Prevention of spontaneous autoimmune diabetes 
in NOD mice by transferring in vitro antigen-pulsed syngeneic dendritic cells. Endocrinology 141:1500-1505

21. Shinomiya M, Fazle-Akbar SM, Shinomiya H, Onji M (1999) Transfer of dendritic cells (DC) ex vivo stimulated with interferon-gamma (IFN-gamma) down-modulates autoimmune diabetes in non-obese diabetic (NOD) mice. Clin Exp Immunol 117:38-43

22. Seissler J, Nguyen TB, Aust G, Steinbrenner H, Scherbaum WA (2000) Regulation of the diabetes-associated autoantigen IA-2 in INS-1 pancreatic beta-cells. Diabetes 49:1137-1141

23. Steinbrenner H, Nguyen TBT, Wohlrab U, Scherbaum WA, Seissler J (2002) Effect of proinflammatory cytokines on gene expression of the diabetes-associated autoantigen IA-2 in INS-1 cells. Endocrinology 143:3839-3845

24. Ohly P, Dohle C, Abel J, Seissler J, Gleichmann H (2000) Zinc sulphate induces metallothionein in pancreatic islets of mice and protects against diabetes induced by multiple low doses of streptozotocin. Diabetologia 43:1020-1030

25. Bach JF (1994) Insulin-dependent diabetes mellitus as an autoimmune disease. Endocr Rev 15:516-542

26. Seissler J, Scherbaum WA (2002) Are we ready to predict and prevent endocrine/organ specific autoimmune diseases? Springer Semin Immunopathol 24:273-295

27. Xu S, Ariizumi K, Caceres-Dittmar G et al. (1995) Successive generation of antigen-presenting, dendritic cell lines from murine epidermis. J Immunol 154:2697-2705

28. Winzler C, Rovere P, Rescigno M et al. (1997) Maturation stages of mouse dendritic cells in growth factor-dependent long-term cultures. J Exp Med 185:317-328

29. Cella M, Sallusto F, Lanzavecchia A (1997) Origin, maturation and antigen presenting function of dendritic cells. Curr Opin Immunol 9:10-16

30. Ardavin C, Martinez-del-Hoyo G, Martin P et al. (2001) Origin and differentiation of dendritic cells. Trends Immunol 22:691-700

31. Schattenberg D, Schott M, Reindl G et al. (2000) Response of human monocyte-derived dendritic cells to immunostimulatory DNA. Eur J Immunol 30:2824-2831

32. Shortman K (2000) Burnet oration: dendritic cells: multiple subtypes, multiple origins, multiple functions. Immunol Cell Biol 78:161-165

33. Martinon-Ego C, Berthier R, Cretin F, Collin V, Laharie AM, Marche PN (2001) Murine dendritic cells derived from myeloid progenitors of the thymus are unable to produce bioactive IL-12p70. J Immunol 166:5008-5017

34. Hochrein H, Shortman K, Vremec D, Scott B, Hertzog P, O'Keeffe M (2001) Differential production of IL-12, IFNalpha, and IFN-gamma by mouse dendritic cell subsets. J Immunol 166:5448-5455

35. De Smedt T, Van Mechelen M, De Becker G, Urbain J, Leo O, Moser M (1997) Effect of interleukin-10 on dendritic cell maturation and function. Eur J Immunol 27:1229-1235

36. Huang LY, Sousa C, Itoh Y, Inman J, Scott DE (2001) IL-12 induction by a TH1-inducing adjuvant in vivo: dendritic cell subsets and regulation by IL-10. J Immunol 167:1423-1430

37. Harada M, Makino S (1984) Promotion of spontaneous diabetes in non-obese diabetes-prone mice by cyclophosphamide. Diabetologia 27:604-606

38. Rothe H, Ito Y, Kolb H (2001) Disease resistant, NODrelated strains reveal checkpoints of immunoregulation in the pancreas. J Mol Med 79:190-197

39. Wegmann DR, Norbury-Glaser M, Daniel D (1994) Insulin-specific $\mathrm{T}$ cells are a predominant component of islet infiltrates in pre-diabetic NOD mice. Eur J Immunol 24:1853-1857

40. Xiao BG, Huang YM, Yang JS, Xu LY, Link H (2001) Bone marrow-derived dendritic cells from experimental allergic encephalomyelitis induce immune tolerance to EAE in Lewis rats. Clin Exp Immunol 125:300-309

41. Legge KL, Gregg RK, Maldonado-Lopez R et al. (2002) On the role of dendritic cells in peripheral $\mathrm{T}$ cell tolerance and modulation of autoimmunity. J Exp Med 196:217-227

42. Rabinovitch A (1998) An update on cytokines in the pathogenesis of insulin-dependent diabetes mellitus. Diabetes Metab Rev 14:129-151

43. Jonuleit H, Schmitt E, Schuler G, Knop J, Enk AH (2000) Induction of interleukin 10-producing, nonproliferating CD4(+) $\mathrm{T}$ cells with regulatory properties by repetitive stimulation with allogeneic immature human dendritic cells. J Exp Med 192:1213-1222

44. Feili-Hariri M, Falkner DH, Morel PA (2002) Regulatory Th2 response induced following adoptive transfer of dendritic cells in prediabetic NOD mice. Eur J Immunol 32:2021-2030 